\title{
THE OXYDASE REACTION OF HUMAN MILK
}

\author{
BY
}

\section{O. S. ROUGICHITCH, M.D., and E. DUMITRESCU, M.D.}

(From the Department of Paediatrics, University of Belgrade, and the Infants' Home, 'Dom Materinskog Udruzenja,' Belgrade.)

Although it has been known for some time that ferments are present in milk, comparatively little attention has been devoted to the question. Not only the nature and source of these ferments but also their rôle in physiology is unknown, so that there is little wonder that their presence has not found any application in practice. Oxydase is a notable exception to this generalization. Since the publication of Raudnitz's work it has been known that this ferment is always present in colostrum. Since then much work has been done, especially by the French, on its presence in normal milk.

Of these latter workers Marfan is the chief, and he alone has made any attempt to use his findings for clinical guidance.

Marfan in his earliest researches was able to confirm Raudnitz's finding that oxydase was always present, and in considerable amount, in colostrum, and later he demonstrated that thereafter it gradually diminished in quantity, but that in at least 95 per cent. of examples it persisted to a certain small degree until the end of lactation, so long as the milk remained normal and the mother healthy. Marfan also showed that when the oxydase reaction in milk continues to be intense even for as short a period as eight days after parturition some suppurative process in the breast is most probably at work. This same author further found that an intense reaction might also occur when breast feeding is interrupted or when stagnation of milk is present. On the other hand, Marfan discovered that the ferment usually disappears from the milk when the secretion is very poor, or when lactation is at an end, and finally that the same may happen temporàrily during menstruation.

Little more can be found in the literature. The present study was undertaken to supplement Marfan's findings.

\section{Material studied}

The milk of fifty women who were admitted with their babies to this Institution during the past year forms the basis of the present communication. The stage of lactation varied from the second week to the tenth month. Thirty-five of the cases were under observation for periods of at least two months, and in the remaining fifteen the period of observation was on the average two weeks.

Technique.-The test for oxydase was carried out in all the cases every third day, samples in the morning, at noon and in the evening always being examined. Three samples of milk were taken separately from each woman for each test; one before breast-feeding, one after breast-feeding and one 
after the breast had finally been emptied by manual expression. Milk was obtained from both breasts so that the secretion from the two sides could be compared. All samples of the milk for examination were obtained by manual expression.

The test for oxydase was carried out immediately after the collection with 1 per cent. solution of guaiacol and hydrogen peroxide. The readings were made after the test tubes had been in the water bath at $50^{\circ} \mathrm{C}$. for five minutes. The intensity of the reaction was recorded in the following manner: \pm incomplete, weak; + complete; ++ complete, moderate; +++ complete, intense; and ++++ complete, very intense reaction.

\section{Results}

As the basis for the interpretation of the results the first thirty-five cases in which the breast feeding remained uninterrupted during the whole period of observation have been taken. The results in the remaining fifteen cases, in so far as they were applicable, have been added to the general statistics.

TABLE.

SHOWING THE OXYDASE REACTION IN 35 NORMAL NURSING WOMEN CARRIED OUT SYNCHRONOUSLY IN MILK FROM RIGHT AND LEFT BREASTS DURING VARYING MONTHS OF LACTATION.

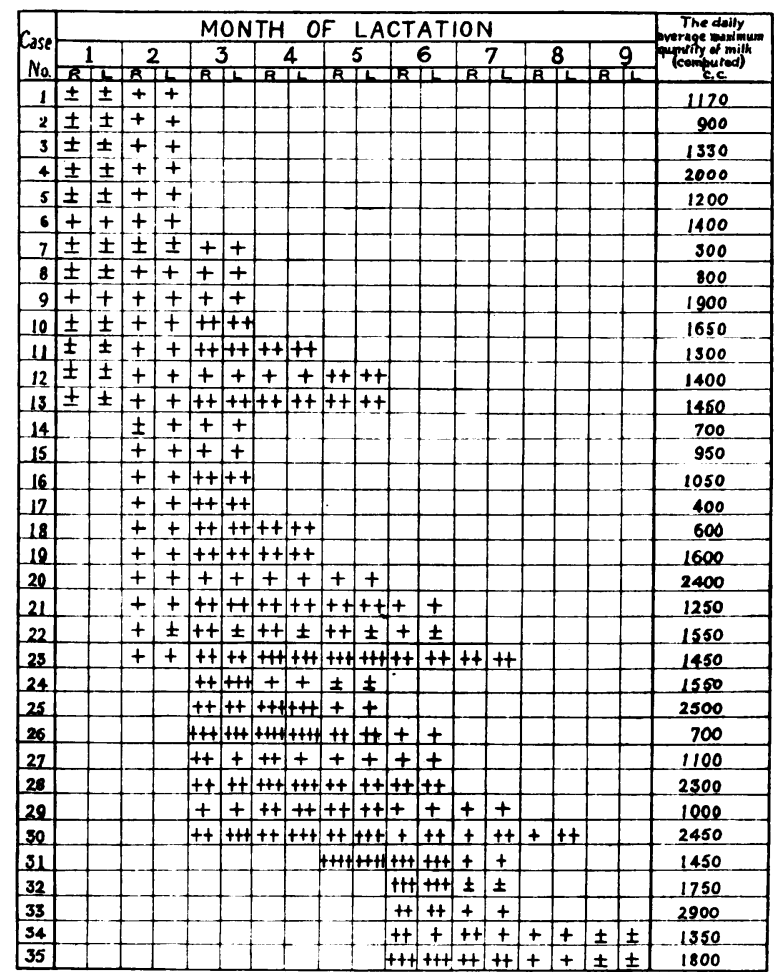

$\mathrm{R}=$ right breast. $\quad \mathbf{L}=$ left breast.

In the first place it is seen from the table that oxydase was present in all the samples of milk tested. It may be mentioned in passing that out of 6,400 tests a positive reaction was obtained in all but five and in these latter other samples from the same mothers gave positive results. 
It is also seen from the table that the oxydase reaction is, as a rule, equally intense in the milk from either side. The only exceptions are cases $14,22,27,30,32$ and 34, but even in these cases the difference between the two sides is not great. It should be recorded that in case 22 an operation had been performed on the left breast during pregnancy. Although the secretion of milk was almost equal from both breasts after parturition, the oxydase reaction in the milk from the left breast remained less intense throughout the period of observation.

In order to ascertain whether there is any relationship between the quantity of milk secreted and the intensity of the reaction the total supply was measured and the daily average output determined. This latter figure is given in a separate column in the table and reveals that there is no constant relationship between these two factors. Hence the degree of the oxydase reaction cannot be taken as an index of efficiency in breast-feeding as some authors have asserted.

Perhaps the most striking feature in the table is the relationship between the intensity of the reaction and the period of lactation. In all cases the reaction became intense from the third month up till the six month of lactation, and thereafter gradually grew less intense.

Some authors have endeavoured to find out if there are other factors, outside the pathological conditions, which influence the intensity of the oxydase reaction. Marfan, for instance, maintains that the reaction is always most intense at the beginning of a breast feed. In forty-three per cent. of the present cases the reaction was most intense before suckling, in forty-seven per cent. after suckling and in ten per cent. the strength of the reaction was the same before and after suckling.

Milk is not constant in its composition. Indeed, variations in certain constituents occur from time to time during the day and in this respect the oxydase ferment is no exception. The cases which were under observation showed that sixty per cent. presented the most intense reaction in the evening, eleven per cent. in the morning and two per cent. at noon, whereas in twenty-seven per cent. the reaction remained constant in intensity throughout the day.

Marfan, as previously noted, maintains that interruption of breastfeeding leads to stagnation of milk in the breast and that in consequence there follows an increase in intensity of the oxydase reaction. The present cases, however, show that the normal nocturnal interval (eight hours) in breast-feeding is too short to produce any appreciable difference in this respect.

In addition to the above cases there has been an opportunity of studying the behaviour of the reaction during menstruation. At the beginning of the flow the reaction was very intense and then gradually became less so, but it never disappeared. 
The test has also been carried out in five cases with mastitis. In all the reaction was similar to that obtained with colostrum and was particularly intense during the first forty-eight hours, afterwards becoming less marked. In one of these cases the number of leucocytes in the milk diminished in proportion to the diminution in the intensity of the reaction. In another example of mastitis, which was under observation, the reaction remained intense until the time of surgical intervention.

Finally, in seven cases of so-called genital crisis in the new-born, the test for oxydase was carried out in the liquid obtained from the breasts, and it was slightly positive in six and negative in one.

\section{REFERENCES}

Sommerfeld, P., Handbuch der Milchkunde, Wiesbaden, 1909, 306.

Marfan, A. B., Traite de l'allaitement, fourth edition, Paris, 1930, 38. 